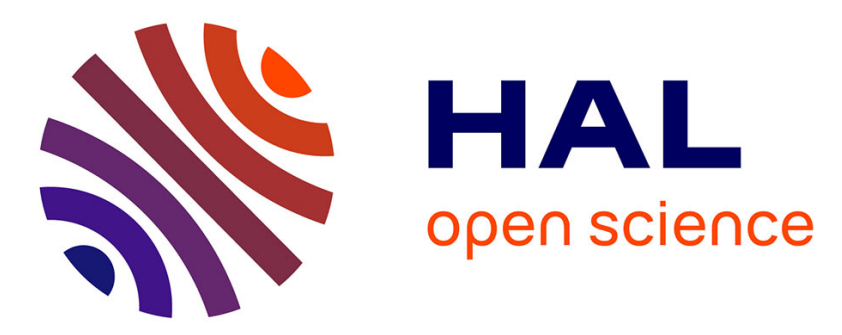

\title{
Analytical applications of infrared semiconductor lasers in atmospheric trace gas monitoring \\ P. Werle
}

\section{To cite this version:}

P. Werle. Analytical applications of infrared semiconductor lasers in atmospheric trace gas monitoring. Journal de Physique IV Proceedings, 1994, 04 (C4), pp.C4-9-C4-12. 10.1051/jp4:1994402 . jpa00252540

\author{
HAL Id: jpa-00252540 \\ https://hal.science/jpa-00252540
}

Submitted on 1 Jan 1994

HAL is a multi-disciplinary open access archive for the deposit and dissemination of scientific research documents, whether they are published or not. The documents may come from teaching and research institutions in France or abroad, or from public or private research centers.
L'archive ouverte pluridisciplinaire HAL, est destinée au dépôt et à la diffusion de documents scientifiques de niveau recherche, publiés ou non, émanant des établissements d'enseignement et de recherche français ou étrangers, des laboratoires publics ou privés. 


\title{
Analytical applications of infrared semiconductor lasers in atmospheric trace gas monitoring
}

\author{
P. WERLE
}

Fraunhofer Institut für Atmosphärische Umweltforschung, Kreuzeckbahnstr. 19, 82467 GarmischPartenkirchen, Germany

\begin{abstract}
Sensitivity, specifity, high time resolution and cost effective simultaneous measurements of several components using operational systems are the main requirements for atmospheric research and air pollution monitoring. Tunable diode lasers absorption spectroscopy (TDLAS) is increasingly beeing used to measure atmospheric trace gas concentrations down to low ppb-levels $\left(10^{-9}\right.$ volume mixing ratio). This optical technique fulfills the requirements for trace gas analysis in the atmosphere for most of the smaller molecules with resolved absorption spectra. Semiconductor lead salt diode lasers give access to the mid infrared spectral region, where the most important atmospheric constituents have strong rotational vibrational absorption bands. The application of high frequency modulation (FM) schemes can further improve sensitivity and detection speed of modern instrumentation.
\end{abstract}

\section{Introduction}

Modern measurements of atmospheric trace gases impose high demands on analytic instrumentation. Fast, accurate, rugged and operational instruments are needed for fast airborne measurements and sensitive and reliable field measurements. Ultrasensitive instruments free of interference by other atmospheric constituents are required to measure free radicals and other reactive species in the atmosphere. The great number of gaseous pollutants and their generally low varyable concentrations with large local differences pose challenging requirements to analytical techniques. Thus, sensitive, selective and mobile or even portable instruments with large dynamic range are needed. Modern research in atmospheric chemistry requires highly sensitive techniques for measurement of concentrations of free radicals which determine the rate of photochemical destruction of most atmospheric pollutants.

Since the development of lasers with high spectral brightness and tunability over broad wavelength ranges, spectroscopic schemes are of growing interest. They are mostly based on absorption measurements. Since the absorption spectrum is characteristic for each molecule, these methods often permit the simultaneous detection of many substances. The list of molecules of environmental concem essentially includes volatile organic compounds ( $\mathrm{HCHO}$, $\mathrm{HCOOH}$ ) yet as nitric oxides $\left(\mathrm{NO}, \mathrm{NO}_{2}, \mathrm{~N}_{2} \mathrm{O}\right)$, ozone $\left(\mathrm{O}_{3}\right)$, ammonia $\left(\mathrm{NH}_{3}\right)$, sulfur dioxide $\left(\mathrm{SO}_{2}\right)$, carbon oxides $\left(\mathrm{CO}, \mathrm{CO}_{2}\right)$, etc. It is obvious, that the mid infrared from 3 to $20 \mu \mathrm{m}$, the so-called "fingerprint region", is the preferable wavelength range. According to Beer's law conventional absorption spectroscopy requires long absorption pathlengths for achieving high sensitivity. Table 1 shows a list of some molecules of interest and the calculated detection limits, which scale linear with the minimum detectable absorbance and the absorption pathlength. Higher sensitivities are expected at longer integration times.

Apart from flexibility as the molecule of interest is concerned, the ease of operation, the complexity of the apparatus as well as the usefulness for field applications have to be considered for practical evaluations. Tunable diode laser absorption spectroscopy (TDLAS) is being frequently used for measurement of trace gas pollutants in the atmosphere ${ }^{3}$. The TDLAS spectrometers usually work with multipass absorption cells to achieve high sensitivity. To alleviate problems by absorption line overlap, these absorption cells are usually operated at low pressure where the linewidth is Doppler limited. In most sensitive instruments the diode laser is repetitively tuned over an absorption line of a target molecule and the absorption spectra are averaged over a specified time interval. Additional modulation techniques are used to reduce the 1/f laser noise. With derivative spectroscopy using lock-in-detection at $\mathrm{kHz}$ modulation frequencies, typically, detection limits of the order of $0.1 \mathrm{ppbv}$ were achieved for many molecules in the air with spectra averaging times of a few minutes ${ }^{4}$. 


\begin{tabular}{|c|c|c|c|c|c|c|c|c|c|c|c|}
\hline \multirow[t]{2}{*}{ Gas } & \multirow{2}{*}{$\begin{array}{c}M \\
{[\mathrm{~g} / \mathrm{Mol}]}\end{array}$} & \multirow{2}{*}{$\begin{array}{c}\tilde{v}_{0} \\
{\left[\mathrm{~cm}^{-1}\right]}\end{array}$} & \multirow{2}{*}{$\begin{array}{c}\lambda \\
{[\mu \mathrm{m}]}\end{array}$} & \multirow{2}{*}{$\begin{array}{c}S / 10^{-20} \\
{[\mathrm{~cm} / \mathrm{molc}]}\end{array}$} & \multirow{2}{*}{$\begin{array}{c}g \\
{\left[\mathrm{~cm}^{-1 / a t m}\right]}\end{array}$} & \multicolumn{2}{|c|}{$\gamma_{V}$} & \multirow{2}{*}{$\begin{array}{c}\sigma_{0} / 10^{-18} \\
{\left[\mathrm{~cm}^{2} / \mathrm{molc}\right]}\end{array}$} & \multirow{2}{*}{$\begin{array}{c}c_{\min }^{S T P} \\
{\left[10^{8} / \mathrm{cm}^{3}\right]}\end{array}$} & \multirow{2}{*}{$\begin{array}{c}D L \\
\text { [pptv] }\end{array}$} & \multirow{2}{*}{$\begin{array}{l}D L^{S T P} \\
{\left[\mu g / m^{3}\right]}\end{array}$} \\
\hline & & & & & & {$\left[\mathrm{cm}^{-1}\right]$} & [MHz] & & & & \\
\hline $\mathrm{CO}_{2}$ & 44.01 & 2270.290 & 4.405 & 3.358 & 0.0740 & 0.00351 & 105 & 3.50 & 42 & 160 & 0.31 \\
\hline$o_{3}$ & 48.00 & 1052.848 & 9.498 & 4.2 & 0.0773 & 0.00264 & 79 & 5.30 & 28 & 100 & 0.22 \\
\hline $\mathrm{N}_{2} \mathrm{O}$ & 44.01 & 2236.224 & 4.472 & 100.4 & 0.0768 & 0.00355 & 106 & 103 & 1.4 & 5 & 0.01 \\
\hline $\mathrm{CO}$ & 28.01 & 2169.198 & 4.610 & 46.15 & 0.0611 & 0.00363 & 109 & 48.9 & 3 & 11 & 0.014 \\
\hline $\mathrm{CH}_{4}$ & 16.04 & 3067.300 & 3.260 & 21.29 & 0.0616 & 0.00577 & 173 & 15.3 & 9.6 & 36 & 0.026 \\
\hline No & 30.01 & 1875.813 & 5.331 & 3.399 & 0.0620 & 0.00326 & 98 & 3.91 & 38 & 140 & 0.19 \\
\hline $\mathrm{SO}_{2}$ & 64.06 & 1371.695 & 7.290 & 4.855 & 0.1200 & 0.00386 & 116 & 4.11 & 36 & 130 & 0.38 \\
\hline $\mathrm{NO}_{2}$ & 46.01 & 1600.413 & 6.248 & 21.8 & 0.0670 & 0.00278 & 83 & 27.7 & 5.3 & 20 & 0.042 \\
\hline $\mathrm{NH}_{3}$ & 17.03 & 930.757 & 10.744 & 52 & 0.0750 & 0.00292 & 88 & 61.8 & 2.4 & 9 & 0.007 \\
\hline $\mathrm{HNO}_{3}$ & 63.01 & 1694.321 & 5.902 & 2.85 & 0.1100 & 0.00375 & 112 & 2.53 & 58 & 220 & 0.60 \\
\hline $\mathrm{H}_{2} \mathrm{CO}$ & 30.03 & 2781.035 & 3.596 & 11.86 & 0.1080 & 0.00517 & 155 & 8.41 & 17 & 65 & 0.087 \\
\hline $\mathrm{H}_{2} \mathrm{O}_{2}$ & 34.01 & 1284.205 & 7.787 & 4.464 & 0.1000 & 0.00352 & 105 & 4.27 & 34 & 130 & 0.2 \\
\hline $\mathrm{HO}_{2}$ & 33 & 1411.182 & 7.086 & 1.2 & 0.090 & 0.00338 & 101 & 1.2 & 120 & 450 & 0.66 \\
\hline
\end{tabular}

Table 1: calculated 1 $\sigma$ Detection Limits DL for selected molecules and molecular absorption lines for a minimum absorbance of $O D_{\min }=10^{-6}$. Assumed are 30 mbar pressure in $25 \mathrm{~m}$ multi path cell $@ 296 \mathrm{~K} . \mathrm{M} \equiv$ Molmass, $\mathrm{S} \equiv$ Linestrength, $\mathrm{g} \equiv$ Pressure broadening coefficient, $\sigma_{0} \equiv$ absorption cross section at line center, $\gamma_{V} \equiv$ Voigt-HWHM, $c_{\text {min }} \equiv$ volume mixing ratio $: 1$ pptv $=10^{-12}$

Although these detection limits are sufficient for many applications, still better detection limits are required by modern atmospheric research for the determination of concentrations of free radicals which play a decisive role in the destruction of almost all atmospheric pollutants and in the formation of tropospheric ozone. Substantial improvements of TDLAS detection limits were obtained by introducing the high frequency modulation technique ${ }^{4,5}$. However, to achieve the sensitivity improvement using the FM technique and to build instruments for routine high sensitivity measurements and even sensitive field applications like trace gas flux measurements, many practical problems still have to be solved.

\section{High frequency modulation spectroscopy}

High frequency modulation technique (FM) applied to tunable diode laser absorption spectroscopy (TDLAS) has the potential to satisfy most of the requirements for sensitivity, specifity, detection speed and applicability for many smaller pollutant molecules. The FM technique which has been invented in 1979 by G. Bjorklund, determines the absorption or dispersion of a narrow spectral feature by detecting the heterodyne beat signal that appears when the FM optical spectrum of the probe wave is distorted by the spectral feature of interest ${ }^{5}$. A modified two tone modulation scheme has been introduced by Cooper and Gallagher. ${ }^{5}$. A potential sensitivity improvement of up to two orders of magnitude in comparison to conventional derivative (2f) spectroscopy can be derived from wideband noise characteristics of lead-salt diode lasers $^{6}$ for both FM-techniques. This sensitivity improvement can be achieved by increasing the modulation frequency from the $1 / \mathrm{f}$ noise dominated region $(10 \mathrm{kHz})$ into a shot noise limited domain of beyond say $100 \mathrm{MHz}$. In terms of optical density the best detection limits obtained so far with a high frequency modulated TDLAS instrument with a multiple pass absorption cell were on the order of $10^{-6}$ with a detection bandwidth of $1 \mathrm{~Hz}^{7,9}$. Since the detection limit in FM-spectroscopy is under these conditions proportional to the square root of the laser power on the detector, the laser output power should be as high as possible. This requirement is further stressed by the use of long absorption paths using multipass cells which strongly attenuate the incoming radiation. The theoretical square root dependence of the detection limit on detector incoming power is only valid under quantum limited conditions, which means that the shot noise has to be the dominating noise source in the system. While the shot noise level is dependent on the incident photon flux, the thermal noise is independent of the laser power. This means that the laser power available after passing through the absorption cell should be high enough to generate a shot noise current which is about one order of magnitude above the thermal noise level. With available detectors this requirement means that lasers for FM use should have an output power of at least $1 \mathrm{~mW}$. However, calibrated power measurements of most of the presently available lasers show values of about several hundreds of $\mu \mathrm{W}$. Due to the limited power output, the FM instruments have to be operated at reduced absorption path length ${ }^{8}$. 
Fig. 1 shows the basic setup of a FM-spektrometer. A If current is superimposed to a current ramp with a dc-offset via a bias-tee to decouple the different current sources. A lead salt diode laser is driven by this current $i_{L}(t)$ and generates $E_{1}(t)$. The electromagnetic field interacts resonant with the rotational-vibrational absorptions of the molecules in the absorption cell. The interaction is described by the complex transmission function $T(\omega)$ which accounts for absorption and dispersion. The electrical field after the probe $E_{2}(t)$ induces a detector current $i_{\gamma f}(t)$, which is fed into the rf input of a double balanced mixer for phase sensitive detection at the modulation frequency $\omega_{r f}$. The time dependent demodulated signal $i_{I F}(t)$ at the IF port of the double balanced mixer is proportional to the concentration of the trace components in the absorption cell.

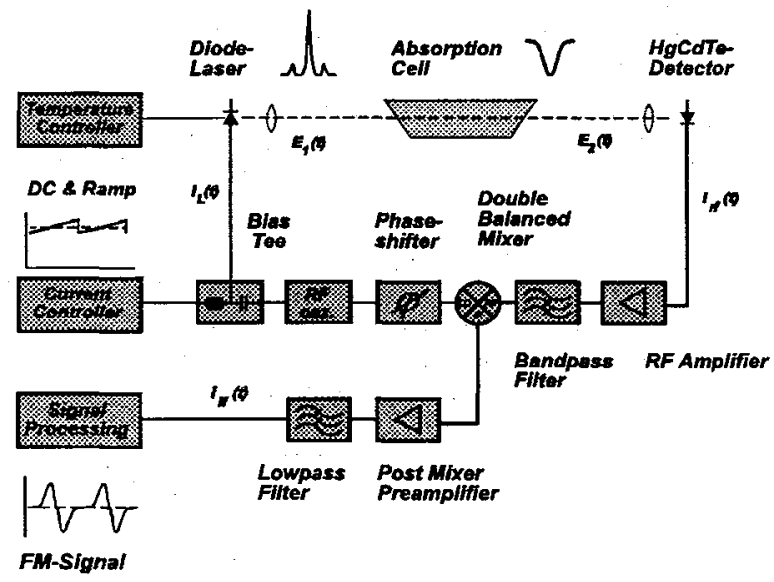

Fig 1 : Principle setup of a FM-spectrometer. For long optical absorption pathlength mostly White or Herriott cells are used.

The signal-to-noise-ratio (SNR) is a convenient way to describe the "cleanliness" of a given signal level. It is simply the signal voltage or power divided by the rms noise voltage (power). A spectrum obtained with a SNR of 100 or more is a very clean pattern, with negligible noise. An SNR of 10 is a little fuzzy, but the pattern is still very clear. A ratio of 3 is pretty bad, and at 1 the signal is nearly lost. If the noise in the detection system is the limiting factor for ultimate sensitivity, the detection limit ( $\left(\mathrm{SNR}^{-1}\right)$ of a spectrometer is proportional to the square root of the detection bandwidth and inverse proportional to the power incident upon the detector, $P_{D}$. Fig. 2 illustrates the dependence of the detection limit for a given set of experimental parameters :

$$
D L \propto \sqrt{\Delta f} \cdot \sqrt{\frac{1+P_{0} / P_{D}}{P_{D}}}
$$

where $P_{0}$ is as system constant describing the power level where shot noise equals the noise of the detector preamplifier combination. There are actually two possible directions towards lower detection limits : increasing the laser power on the detector and bandwidth reduction, i.e. longer integration times. For a laser power $P_{D} \gg P_{0}$ the detection limit is proportional to $P_{D}-1 / 2$, for $P_{D} \ll P_{0}$ it is proportional to $P_{D}{ }^{-1}$. As far as laser power is concerned our work is limited to characterisation and selection of commercially available lasers. The second direction for further improvement of the sensitivity is digital signal averaging. A critical factor influencing the high sensitivity measurements is the system stability, especially at low optical densities below $10^{-5}$. At these sensitivities interference fringes due to unwanted étalons are becoming the factor limiting further improvement of the detection limits ${ }^{7,9}$. In principle, the problem of fringe limitation can be solved by subtraction of zero air spectrum from the measurement spectrum. Trace gas measurements near to the detection limit are, therefore, usually performed by measuring alternatively the spectrum of the ambient air and the spectrum of zero air, i.e. air devoid of the target substance. This procedure is based on the inherent assumption that within the time interval needed for the acquisition of both the measurement and the background spectra the fringes do not move. If this assumption is fulfilled, the subtraction of the background spectrum from the measurement spectrum would provide the absorption spectrum of the target species which, to a first approximation, is only subject to random noise. 
Unfortunately, real systems are not stable forever and it is obvious that every real unstable system will have an optimum averaging time given by the drifts in the system such as temperature drifts, moving fringes, background changes etc. Therefore, a quality of the spectrometer can be described by the characteristics of the instrument stability 9 . To achieve the best possible sensitivity, the instrument should be made as stable as possible and the measuring time should be as short as possible. The real time signal analysis is made by a signal processing board using complex data reduction software. The instrument automatically provides signal, background and calibration spectra which can be averaged up to more that $10^{4}$ individual spectra. Subsequently, a multiple linear regression is performed to fit the background and the calibration spectra simultaneously to the ambient air spectrum. A simultaneous multiple regression analysis also allows us to apply different filters. The Allan variance analysis ${ }^{9}$ predicts the optimum integration time to be about $60 \mathrm{~s}$ for this particular instrument. Within this time a complete measurement sequence consisting of the determination of the ambient air, zero air, and calibration gas spectra has to be completed. Ambient measurements were made with a $\mathrm{NO}_{2}$ doublet line at $1600.413 \mathrm{~cm}^{-1}$ since its background was almost free of disturbance from pressure broadened $\mathrm{H}_{2} \mathrm{O}$ lines nearby. $\mathrm{A} \mathrm{NO}_{2}$ concentration of $1 \mathrm{ppb}$ in the following data corresponds to an optical density of about 5.3 $\cdot 10^{-5}$. A characteristic spectrum is shown in Fig. 3 . The spectra have been averaged 256 times within 740 $\mathrm{ms}$ to obtain a high SNR. The electronics bandwidth had been set to $1.5 \mathrm{kHz}$. In the subsequent regression analysis the measured spectrum has been fittet to the calibration spectrum. The fit reported a concentration of $1.17 \mathrm{ppb}$ with an $1 \sigma$ error of $31.5 \mathrm{ppt}$. The data $(1.17 \pm 0.0315 \mathrm{ppb})$ of Fig. 3, which are well above the detection limit, correspond to an optical density of $(62 \pm 1.7) \cdot 10^{-6}$ at $5.86 \mathrm{~Hz}$ bandwidth.

The previous analysis shows that FM-spectroscopy is

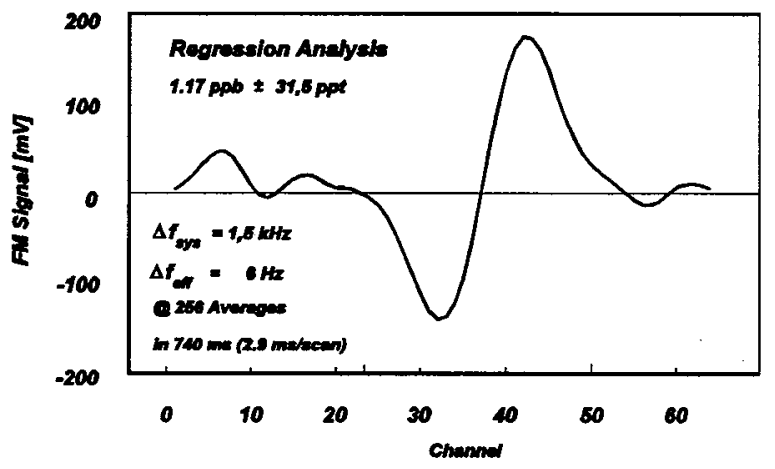

Fig. $3: 1.17 \mathrm{ppb} \mathrm{NO}$-FM-signal from ambient air a very powerful tool for ultrasensitive trace gas analysis. It fulfils most of the requirements for atmospheric trace gas monitoring in ambient air, because it allows fast, sensitive and interference free detection of pollutants at sub-ppb levels. Nevertheless there are many other applications of this technique like quality control of high purity gases for semiconductor processing or breath analysis in medicine.

\section{Acknowledgement}

This work has been funded by the German Ministry for Research and Technology (BMFT) and by the Bayerische Staatsministerium für Wirtschaft und Verkehr.

\section{References}

1. B.J. Finlayson-Pitts, J.N. Pitts, Jr.: Atmospheric Chemistry (Wiley, New York 1986) p. 326

2. H.I. Schiff and U. Platt (eds.) Optical Methods in Atmospheric Chemistry, Proc. SPIE Vol. 1715 (1993)

3. C.R. Webster, R.T. Menzies, E.D. Hinkley: In Laser Remote Chemical Analysis ed. by R.M. Measures (Wiley, New York 1988) p. 163

4. R. Grisar, H. Böttner, M. Tacke, G. Restelli (eds.): Monitoring of Gaseous Pollutants by Tunable Diode Lasers (Kluwer, Dordrecht 1992).

5. P. Werle, F. Slemr, M. Gehrtz and Chr. Bräuchle, "Quantum-limited FM-spectroscopy with a lead-salt diode laser", Appl. Phys. B 49, 99 (1989) and literature cited there.

6. P. Werle, F. Slemr, M. Gehrtz and Chr. Bräuchle, "Wideband noise characteristics of a lead-salt diode laser: possibility of a quantum noise limited TDLAS performance", Appl. Opt. 28, 1638 (1989).

7. D.S. Bomse, A.C. Stanton and J.A. Silver, "Frequency modulation and wavelength modulation spectroscopies: comparison of experimental methods using a lead-salt diode laser", Appl. Opt. 31, 718 (1992).

8. P. Werle and F. Slemr, "Signal-to-noise ratio analysis in laser absorption spectrometers using optical multipass cells", Appl. Opt. 30, 430 (1991).

9. P. Werle, R. Mücke and F. Slemr, "The limits of signal averaging in tunable diode laser absorption spectroscopy", Appl. Phys. B 57, 131-139. (1993) and literature cited there. 